\title{
Magnetospheric source region of discrete auroras inferred from their relationship with isotropy boundaries of energetic particles
}

\author{
A. G. Yahnin ${ }^{1}$, V. A. Sergeev ${ }^{2}$, B. B. Gvozdevsky ${ }^{1}$, S. Vennerstrøm ${ }^{3}$ \\ ${ }^{1}$ Polar Geophysical Institute, Apatity, Murmansk region, 184200, Russia \\ Tel: + 78155537 475; Fax: + 781555 30925; e-mail: yahnin@pgi-ksc.murmansk.su \\ ${ }^{2}$ Institute of Physics, University of St. Petersburg, St. Petersburg, Russia \\ ${ }^{3}$ Danish Meteorological Institute, Solar-Terrestrial Physics Division, Copenhagen, Denmark
}

Received: 27 September 1996 / Revised: 26 February 1997 / Accepted: 14 March 1997

\begin{abstract}
According to observations, the discrete auroral arcs can sometimes be found, either deep inside the auroral oval or at the poleward border of the wide (socalled double) auroral oval, which map to very different regions of the magnetotail. To find common physical conditions for the auroral-arc generation in these magnetotail regions, we study the spatial relationship between the diffuse and discrete auroras and the isotropic boundaries (IBs) of the precipitating energetic particles which can be used to characterise locally the equatorial magnetic field in the tail. From comparison of ground observation of auroral forms with meridional profiles of particle flux measured simultaneously by the low-altitude NOAA satellites above the ground observation region, we found that (1) discrete auroral arcs are always situated polewards from (or very close to) the IB of $>30-\mathrm{keV}$ electrons, whereas (2) the IB of the $>30$ $\mathrm{keV}$ protons is often seen inside the diffuse aurora. These relationships hold true for both quiet and active (substorm) conditions in the premidnight-nightside (1801-h) MLT sector considered. In some events the auroral arcs occupy a wide latitudinal range. The most equatorial of these arcs was found at the poleward edge of the diffuse auroras (but anyway in the vicinity of the electron IB), the most poleward arcs were simultaneously observed on the closed field lines near the polar-cap boundary. These observations disagree with the notion that the discrete aurora originate exclusively in the nearEarth portion of plasma sheet or exclusively on the PSBL field lines. Result (1) may imply a fundamental feature of auroral-arc formation: they originate in the current-sheet regions having very curved and tailwardstretched magnetic field lines.
\end{abstract}

Correspondence to: A. G. Yahnin

\section{Introduction}

Being visible in global scale, the auroras provide the images of global dynamics of the magnetospheric processes. A remarkable feature and important manifestation of the magnetospheric substorm is the auroral dynamics: it starts from the brightening of the most equatorial discrete auroral arc and continues as the development of the auroral bulge (Akasofu, 1968), which forms by continuous poleward motion of the bright discrete arc and/or by progressive poleward formation of new arcs (Sergeev and Yahnin, 1979). There are many different modifications of global auroral dynamics and many different particular auroral structures involved in the substorm process which still have to be understood (Elphinstone et al., 1996).

One of the problems in the interpretation of auroral images in terms of the magnetospheric processes is that we still know very little about the mechanisms of auroral-arc formation and, particularly, about the magnetospheric domains where these arcs can be formed. A straightforward method, mapping the auroral arcs into the magnetosphere using the available magnetospheric models, cannot give reliable results because these statistical models represent some averaged magnetospheric configurations. Also, it is very often difficult to select which of these models is appropriate for the more accurate mapping. Therefore, in discussion of the source regions of auroral arcs the authors rely on some indirect evidence basically obtained from observations of low-altitude spacecraft. The discussion on the sources of auroral precipitation has a long history (see e.g. the reviews by Feldstein and Galperin, 1985; Galperin and Feldstein, 1991; Feldstein and Elphinstone, 1992; Weiss et al., 1992; Elphinstone et al., 1995; Newell et al., 1996). All authors generally agree that the source region of the diffuse aurora is the inner, near-Earth plasma sheet; it is the origin of the discrete auroras that is a main subject of discussion. 
Two basic schemes were disputed. The first of them emphasised that discrete auroras (hereafter we use this term in a more general sense as the name for very structured precipitation) are often seen in the poleward part of the auroral precipitation (referred to in the following as the auroral zone, to retain the original name "oval" for the statistical pattern of the discrete forms). Lyons and Evans (1984) and Lyons et al. (1988) suggested that they come from the outermost part of the magnetotail current sheet and associated this precipitation with the plasma-sheet boundary layer (PSBL) population (Eastman et al., 1984). This type of situation is quite typical for the recovery phase of a substorm where the so-called "double oval" is formed (Elphinstone et al., 1995); it is also typical for long-duration events of the steady magnetospheric convection (SMC) (e.g. Yahnin et al., 1994a; Sergeev et al., 1996). The overlapping of poleward bright part of the double oval with the velocity-dispersed ion structures (VDIS) (Kovrazhkin et al., 1987; Zelenyi et al., 1990), as well as the mapping in the specially prepared magnetospheric model for two SMC events (Sergeev et al., 1996), both confirmed that these high-latitude discrete auroras come from the far tail or PSBL.

Another scheme, proposed by Feldstein and Galperin (1985) and Galperin and Feldstein (1991), placed the earthward edge of the discrete-arc source region deep into the inner magnetosphere. They introduced the term "remnant layer" for the region between the plasmapause and inner edge of the electron plasma sheet and associated this region with the diffuse auroras. In their scheme the remnant layer lies inside the trapping boundary of the energetic electrons. Accordingly, they mapped the discrete precipitation into the rest of the plasma sheet, situated tailwards of the trapping boundary [see also the papers by Vorobjev et al. (1976) and Weiss et al. (1992)]. In the first version of their scheme Feldstein and Galperin called this region the lowlatitude (near-Earth) plasma sheet, and in those following, the main plasma sheet. The main argument in favour of this scheme is that the discrete arcs sometimes can be preferentially observed deep inside the wide auroral zone, near the electron trapping boundary. Such a situation prevails, for example, during the substorm growth phase and at substorm onset (Elphinstone et al., 1996).

From this short overview one can see that there are definitely some specific states of the magnetosphere during which the auroral arcs prefer to appear in different places, being far apart from each other and, more importantly, being very different in their physical characteristics. Therefore, a question arises: Are these arcs generated by the same or different processes? To answer this question one should compare the properties of these regions at times when the discrete auroras tend to appear there (average parameters of regions may be misleading since there may be alternatively favourable/ unfavourable situations for the auroras to occur).

In this paper we attempt to clarify this question by comparing the positions of discrete auroral arcs (and diffuse precipitation as well) with simultaneously ob- served isotropic boundaries (IBs) of energetic protons and electrons. As shown by Sergeev et al. (1993), in most of cases this isotropic precipitation (over the loss cone) is formed by the non-adiabatic "regular scattering" of particles in the equatorial regions where magnetic field line curvature is comparable (or larger) to the particle gyroradius. Correspondingly, the fact of observation of the isotropic boundary in that flux tube means that in the equatorial plane (in the current sheet) a known relationship holds true for the magnetic field $\left(B_{z}\right)$ and current density (via the parameter $d B_{x} / d Z$ entering this relationship). The equatorial $B_{z}$ is the basic controlling factor, and therefore the isotropic boundary may serve as a low-altitude landmark of the specific magnetic field value at the equator. For example (Sergeev et al., 1993), the proton IB (at $E>30 \mathrm{keV}$ ) and the electron IB (the same energy) have the characteristic threshold $B_{z}$ values of about $\sim 30$ and $\sim 5 \mathrm{nT}$, which correspond to the dipole-like region and very stretched and highly curved magnetic field line region, respectively. The observations of isotropic precipitation mean that the equatorial magnetic field is less than the cited threshold values. Using these ideas, our task in this paper is to characterise the magnetospheric domain of auroral-arc appearance in terms of equatorial magnetic field (or more exactly, in terms of magnetic field curvature) in that flux tube. Here we use the ground-based auroral observations to monitor the locations of the auroral arcs at times when NOAA-type spacecraft passed over the observation region measuring energetic particles and providing information on the isotropic precipitation and isotropic boundaries.

Before the data consideration it is important to make some remarks on the terminology used in this paper. As noticed by Newell et al. (1996), the use of the same terms to describe the precipitation patterns observed by different instruments can often lead to disagreement in the interpretation. In this paper we use the terms "discrete aurora" and "discrete auroral arcs" to describe well-isolated narrow ( $\ll 100 \mathrm{~km})$ auroral forms having a well-defined border corresponding to the low-altitude edge of the form. During disturbed intervals such auroral forms often exhibit the ray structure, as well as the curls and surges of different scales moving along the disturbed "discrete arc". The term "diffuse aurora" is used here to describe the wide regions (more than $100 \mathrm{~km}$ ) of the enhanced (relative to the background level) and relatively unstructured luminosity, as is seen from the all-sky-camera films. The latter type includes not only a stable auroral luminosity band but, for example, such auroral forms as the auroral torch-like structure.

\section{Description of data and observations}

Energetic particle data for this study came from similar low-altitude spacecraft TIROS, NOAA-6 and NOAA-7; we had at our disposal the data for August 1979 and November 1981. The peculiarity of the TIROS/NOAA orbit is that in the northern hemisphere the spacecraft 
Table 1. Ground stations and their coordinates

\begin{tabular}{lcc}
\hline Station name & Geogr. latitude & Geogr. longitude \\
\hline Loparskaya & 68.356 & 33.08 \\
Molodezhnaya & -67.67 & 45.85 \\
Novolazarevskaya & -70.77 & 11.83 \\
Scoresbysund & 70.48 & 338.03 \\
Sondre Sromfjord & 67.00 & 309.30 \\
Narssarssuaq & 61.10 & 314.03 \\
\hline
\end{tabular}

orbit covers mainly the dayside half of the auroral zone, whereas the nightside is best covered in the southern hemisphere. For August 1979 we examined the recordings of auroral all-sky cameras at Russian Antarctic stations in the southern hemisphere. We found nine events of the satellite passes over the stations Molodezhnaya and Novolazarevskaya which have been supported by all-sky observations. We also considered the observations made in the northern hemisphere during the steady magnetospheric convection (SMC) event on 24 November 1981. This event is a good example of the "double oval", which is well documented by auroral and other observations [see Yahnin et al. (1994a) for more detailed description]. A few all-sky cameras at Greenland and Kola Peninsula operated during that day, and on two occasions we had simultaneous ground and spacecraft observations in the same region. Coordinates of ground stations used are listed in the Table 1.

The NOAA satellites are low-altitude $(850-\mathrm{km})$ polar orbital satellites measuring particles with three instruments (Hill et al., 1985). The TED instrument measures particles with energies from 0.3 to $20 \mathrm{keV}$. Sensors of the MEPED instrument detect the electrons and ions with energies more than $30 \mathrm{keV}$, and the HEPAD instrument is for protons and alpha articles with energies $>0.37$ $\mathrm{MeV}$ and $0.6 \mathrm{MeV} /$ nucleon, respectively. For our aims (detection of the IBs and comparison with auroras) the MEPED and TED data are suitable. The electron detector of the MEPED instrument has three passbands: $>30,>100$ and $>300 \mathrm{keV}$. The proton telescope selects protons within energy ranges of 30-80, 80-250 keV, etc. Both electrons and protons are measured by the two detectors mounted to view outwards along the Earthsatellite radial vector and along the direction just perpendicular to this vector, respectively. Thus, at latitudes greater than $30^{\circ}$ the detectors are able to register the particles both inside and outside the loss cone. Figure 1 presents the MEPED and TED data for the considered events along with the locations of the visual auroral forms. The IBs of electrons with energies $>30$ and $>100 \mathrm{keV}$ and protons with energies $>30$ and $>80 \mathrm{keV}$ are marked. Note that the IB latitude decreases with an increase in the particle rigidity. This feature can be used as a criterion to distinguish the particle scattering due to small radius of curvature of the magnetic field lines (Sergeev et al., 1993) from the scattering due to intense wave turbulence (e.g. cyclotron wave activity). The latter mechanism is common for late-morning electron precipitation, but can sometimes also operate in the other MLT sectors. As pointed by Sergeev et al. (1993), the isotropic electron precipitation can be interrupted a few times by precipitation with empty loss cone features, and correspondingly, one may observe the multiple isotropic boundary for $>30-\mathrm{keV}$ electrons at one traversal of the auroral zone. This feature naturally follows from "regular scattering" mechanism because of possible non-monotonous behaviour of small $B_{z}$ in the distant current sheet [see Fig. 3 in Sergeev et al. (1993)]. In some cases presented in Fig. 1 such a structure is sometimes seen (see, for example, Fig. 1a, d, f, k). The upper panel of each part of Fig. 1 shows the energy flux of precipitating lowenergy $(0.3-20-\mathrm{keV})$ electrons measured by the TED instrument. Typically the flux pattern can be separated into two parts: the poleward part consisting of a number of spikes (the width of spikes is some tens of kilometres) and the equatorward part in which the flux intensity changes rather smoothly. Obviously, these two parts correspond to the BPS and CPS types of precipitation of Winningham et al. (1975). The energy flux spikes likely correspond to the inverted Vs.

For the comparison, those NOAA/TIROS orbits were selected which crossed the auroral zone inside (or very close to) the field of view of all-sky cameras operated during the time of crossing. Both satellite trajectories and detected auroral forms were mapped to the common altitude $110 \mathrm{~km}$ and put on the map in the invariant latitude - MLT coordinates. These maps are shown in Figs. 2 and 3, and the location of the discrete and diffuse auroral forms are marked in Fig. 1 by asterisks and bars, respectively.

\section{Description of events and results of the comparison}

Table 2 presents a summary of observations. It contains the date and time of event, MLT, invariant latitudes of auroras and IBs. Also, the characteristics of geomagnetic conditions during the events are presented. We will describe the events briefly, presenting first the observations made in August 1979 and then those made in November 1981.

\subsection{Auroras and Isotropic Boundaries}

3.1.1 August 1979. Figure 2a-d shows the AE index, satellite tracks and location of the auroras during the measurements in the evening sector (Events 1-4). The auroral observations were made at the station Molodezhnaya, the location of the arcs is shown by the dashed line. The positions of the IBs for $>30-\mathrm{keV}$ electrons and $>30-\mathrm{keV}$ protons (see Fig. 1a-d) are marked by circles and asterisks, respectively, along the satellite trajectory. The time of the satellite pass is shown by the arrow on the AE plot. The indices exhibit quiet and moderate levels of the activity (from 100 to $700 \mathrm{nT}$ ). As seen from Fig. 2a-d all auroral arcs are found just poleward of the isotropic boundary of $>30-\mathrm{keV}$ electrons. The proton IB has been found well equatorward $(200-400 \mathrm{~km})$ of the arcs. Similar data for the night sector are shown in Fig. 2e,f (Events 5 and 6). These 
NOAA-6 27 August 1979 18:16 - 18:20 UT
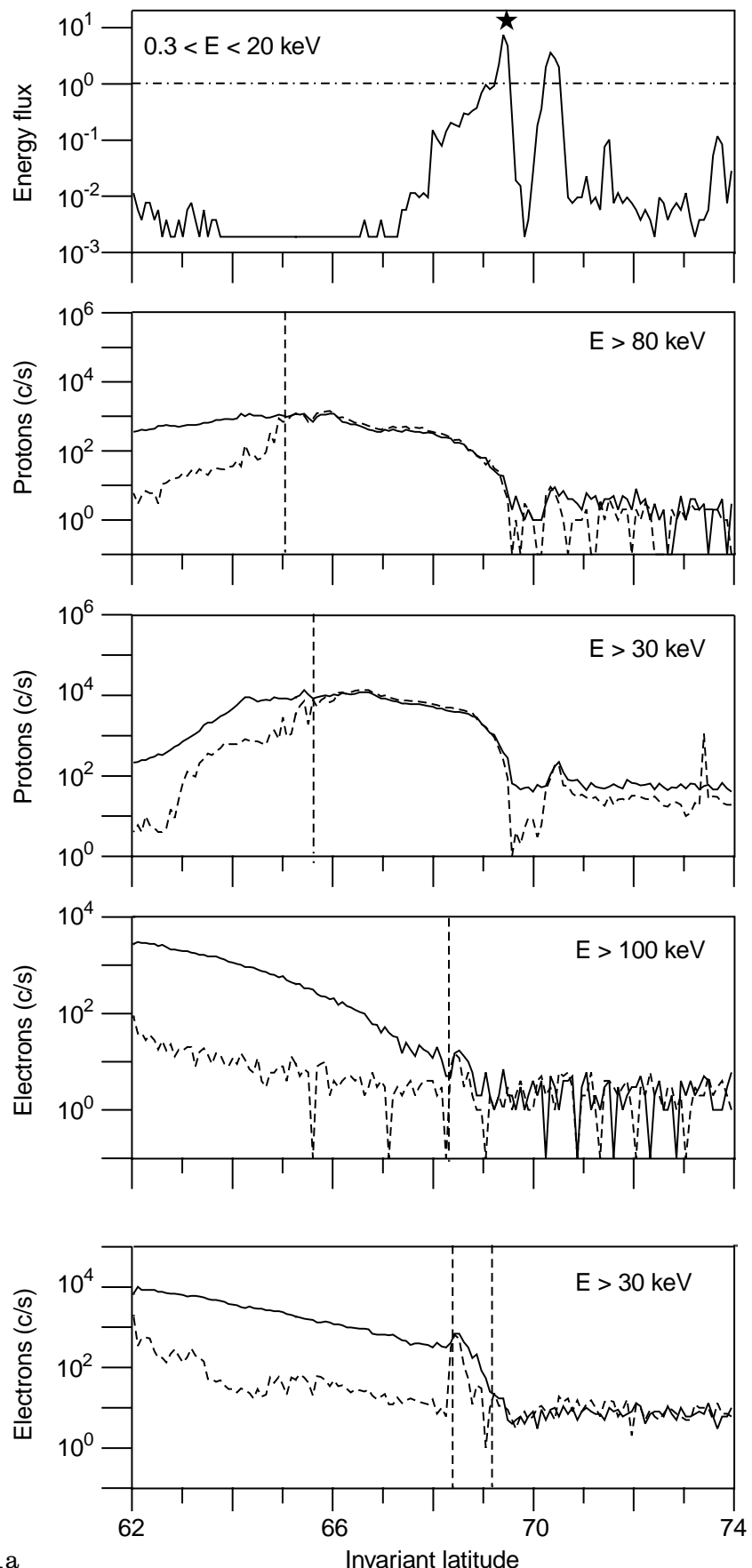

$1 \mathrm{a}$

Invariant latitude

Fig. 1. a. (Event 1) Particle measurements on board the TIROS NOAA satellites made during the crossings of the aurora at 18161820 UT of 27 August 1979. From top to bottom: the differential flux of the $0.3<E<20 \mathrm{keV}$ electrons measured by the TED instrument; count rates of the energetic protons with energies $>80$ and $>30 \mathrm{keV}$, count rates of energetic electrons with energies $>100$ and $>30 \mathrm{keV}$. For energetic particles both trapped (solid line) and precipitating (dashed line) fluxes are presented. Vertical dashed lines mark the isotropy boundaries for energetic particles. Horizontal dashed line at the top panel shows the energy flux level $1 \mathrm{ergs} / \mathrm{cm}^{2} \mathrm{~s}^{*} \mathrm{sr}$. Asterisks mark the location of the discrete auroral arcs as observed by the allsky cameras. (Note that in this case the double IB of the $>30-\mathrm{keV}$ electrons was observed, see text for explanation.) b (Event 2) Likewise
NOAA-6 26 August $1997 \quad$ 18:37 - 18:42 UT
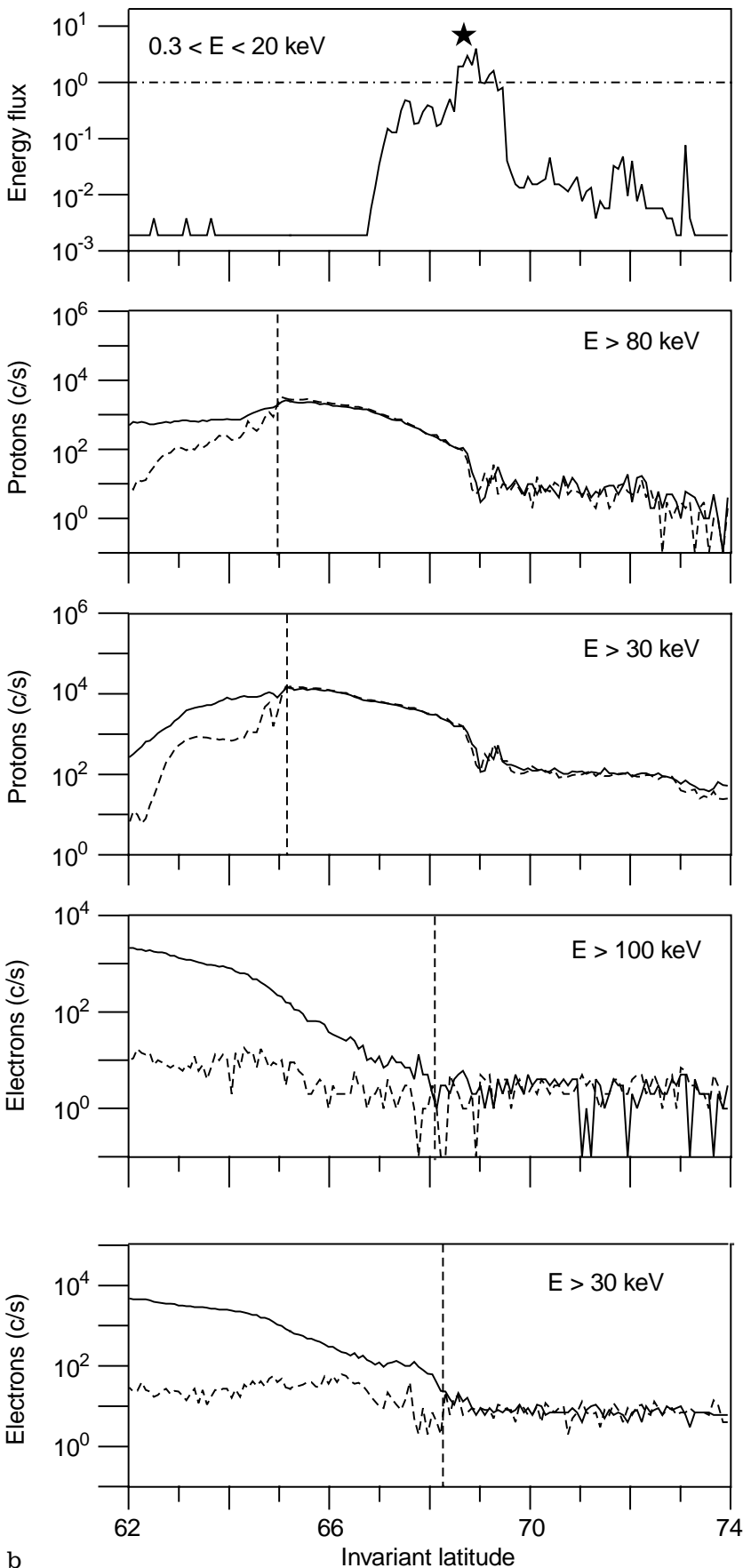

for 1837-1842 UT 26 August 1979. c (Event 3) 1844-1849 UT 21 August 1979. d (Event 4) 1912-1916 UT 15 August 1979. e (Event 5) 2200-2204 UT 01 August 1979.f (Event 6) 2255-2301 UT 15 August 1979. g (Event 7) 2332-2338 UT 21 August 1979. Horizontal hard solid bars mark the latitudinal region occupied by the diffuse auroras. h (Event 8) 0003-0012 UT 19 August 1979. No discrete auroral forms were detected during this crossing. i (Event 9) 0147-0154 UT 19 August 1979. Note that in this case it is impossible to determine the exact location of most equatorward auroras because they were very far from zenith of the all-sky camera. j (Event 10) 1721-1726 UT 24 November 1981 (SMC). k (Event 11) 2041-2046 UT 24 November 1981 (SMC) 
NOAA-6 21 August 1979 18:44 - 19:49 UT
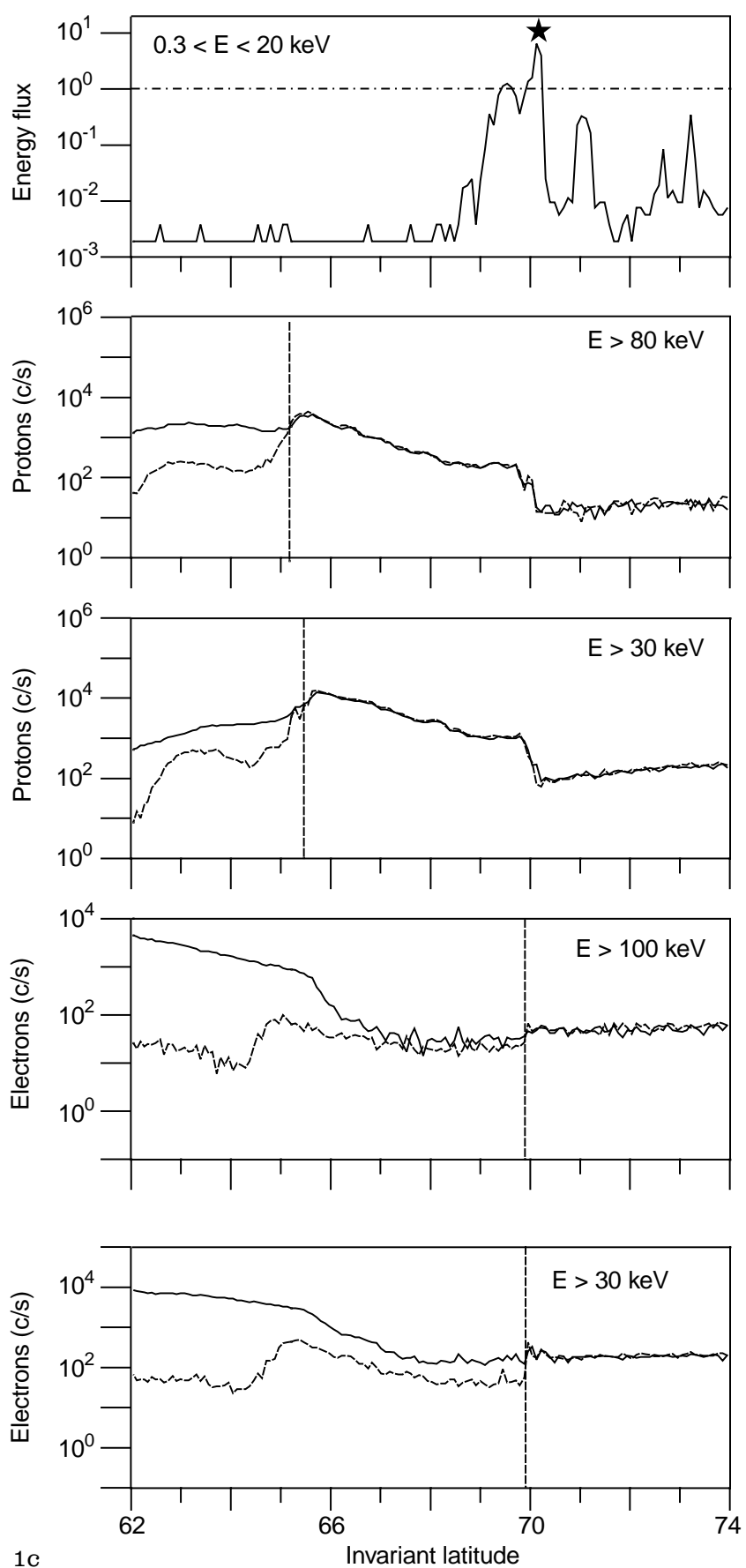

examples include a very quiet period (Event 6) and interval between two substorms (Event 5); They exhibit the same relationship between the locations of the arc and IBs as in the evening sector.

Figure $2 \mathrm{~g}-\mathrm{i}$ (see also Fig. 1g-i) presents the examples of the crossings over the diffuse aurora (Events 7-9). In spite of the low magnetic activity level during Event 7 (Fig. 2g), the poleward boundary of the diffuse auroras (shown by dots) was rather dynamic, and during the satellite pass it exhibited a torch-like structure. The diffuse aurora was bordered from the poleward side by the discrete auroral structure, further poleward the
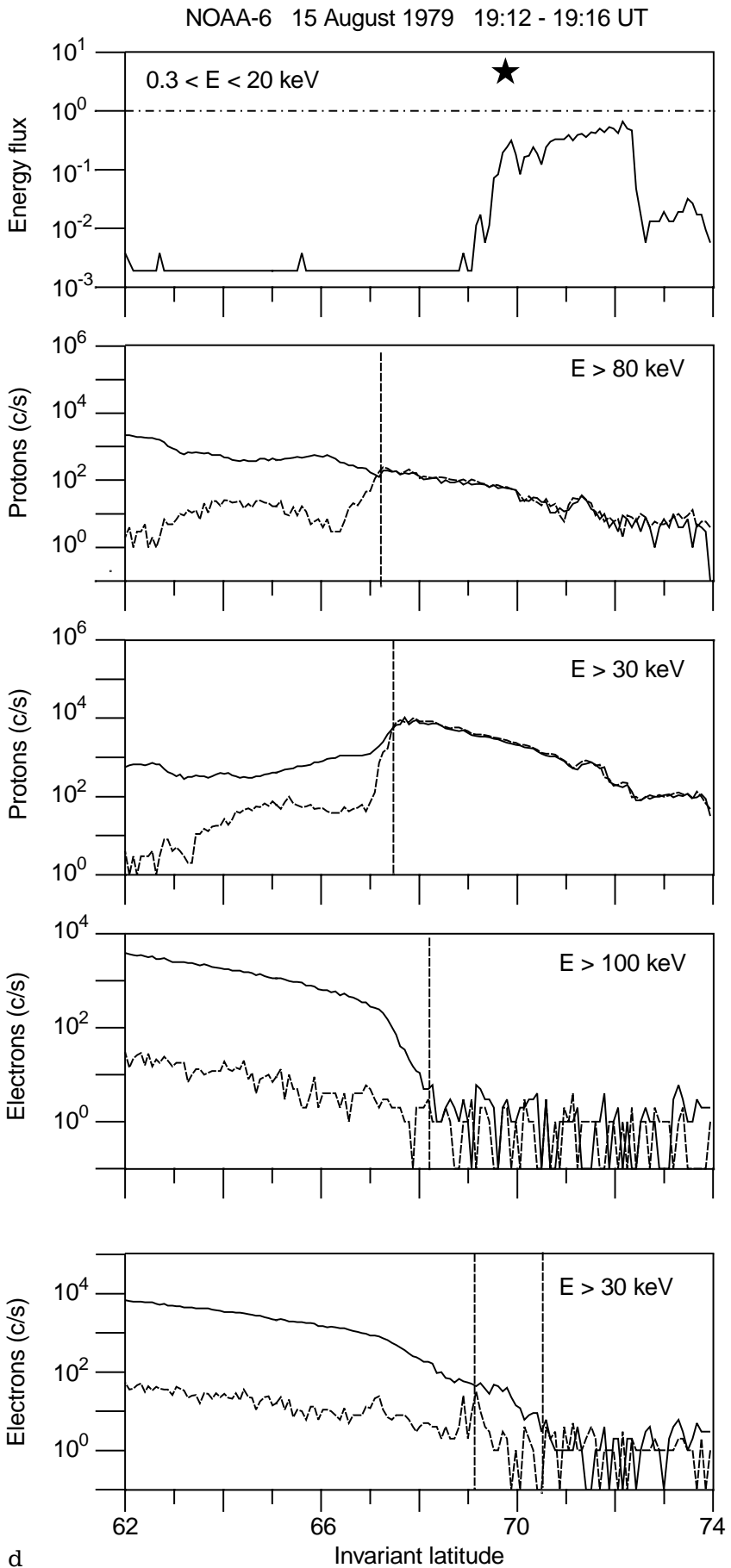

dynamic discrete structures were seen. In this more complicated and dynamic case again all discrete structures lie polewards of the electron IB, whereas the diffuse auroras appear equatorward of this IB. Most intense diffuse auroras coincide with the region where the proton IBs are found.

Other two cases of diffuse aurora were observed when the magnetic activity was very strong (up to 1000 nT). The all-sky camera at Novolazarevskaya (inv. lat. $=-62.8$ ) observed the diffuse glow filling the wide latitudinal range, but the most intense auroral band was registered just equatorwards of the zenith for the case of 

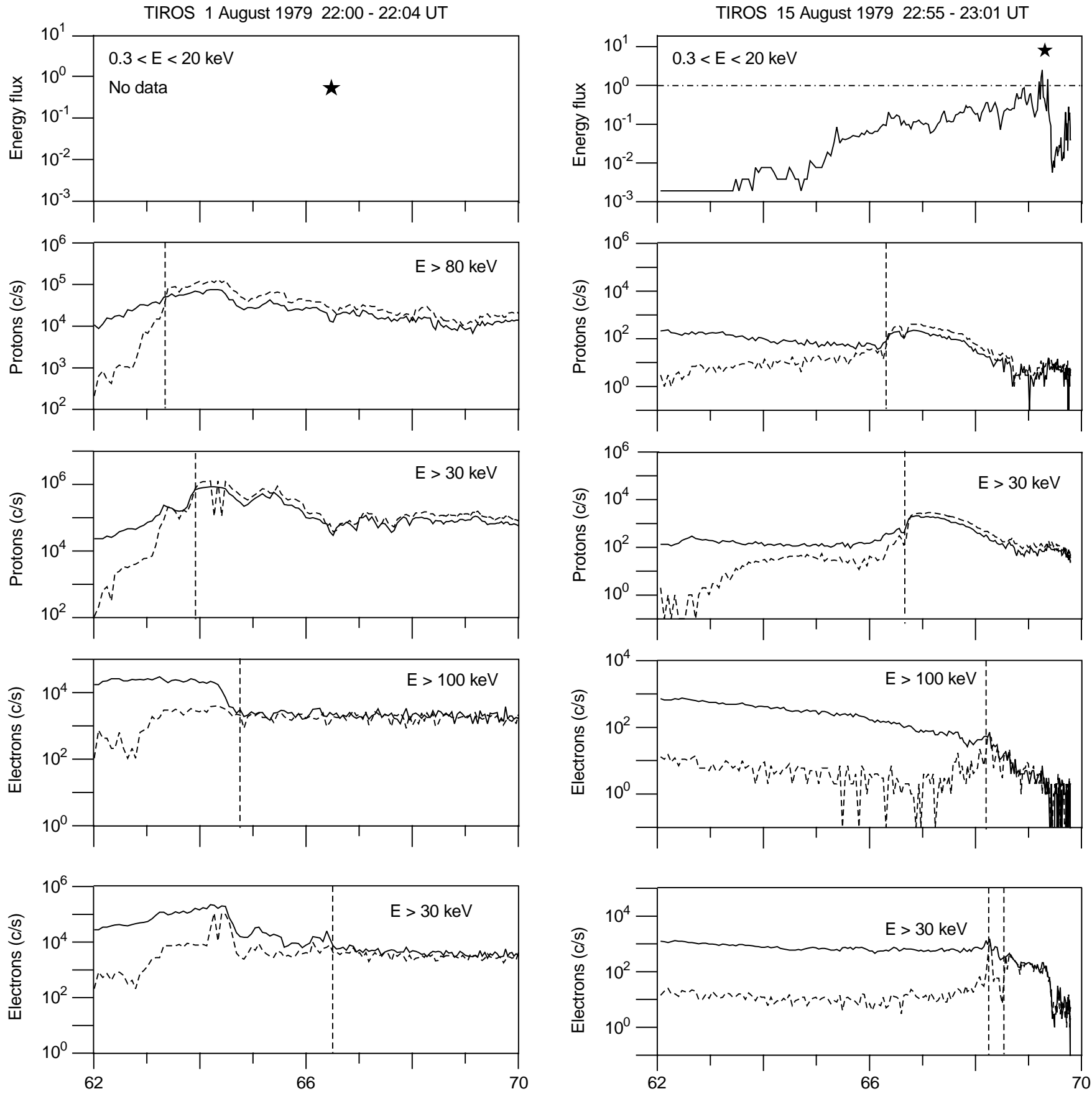

$1 \mathrm{e}$

Invariant latitude

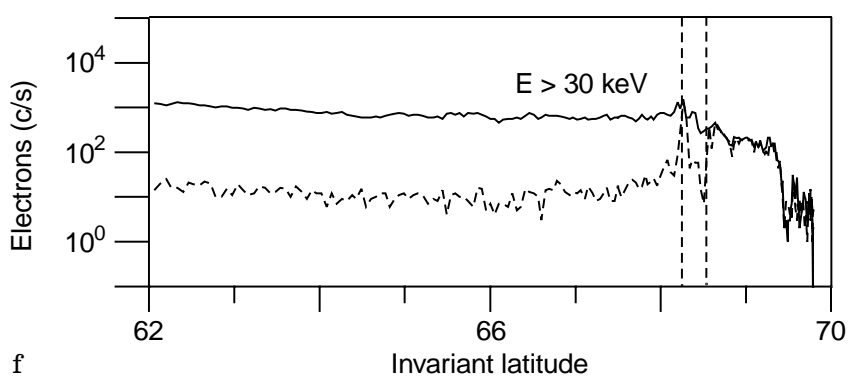

the Event 8 (Fig. 2h). From this figure (see also Fig. 1h) it is clear that the electron IB is far to the pole from this band. The proton IBs are found just at latitudes of the intense diffuse auroral band. Event 9 (Figs. 1i and 2i) exhibits an interesting situation which sometimes occurs during very strong magnetic activity intervals. All IBs, both for protons and for electrons, coincided (at least, within the 2-s resolution of the TIROS satellite measurements), and they were located at very low latitude (inv. lat. $=58.5$ ). The diffuse auroras were very intense and formed huge torch-like structures. Although these auroras were far from the zenith, at the equatorial edge of the all-sky-camera field of view, and although it is

difficult to determine their location very accurately, it seems that the IBs are at the latitudes of the diffuse auroras. There were also some discrete auroral forms seen at the sky of Novolazarevskaya. All these forms are situated polewards of the IBs.

3.1.2 24 November 1981. A detailed description of the SMC interval of 24 November 1981 is given in Yahnin et al. (1994a). A rather stable auroral distribution pattern was observed during that day as shown by both the ground-based observations and the DE-1 imager data. It consisted of the $b$ and of intense diffuse aurora 

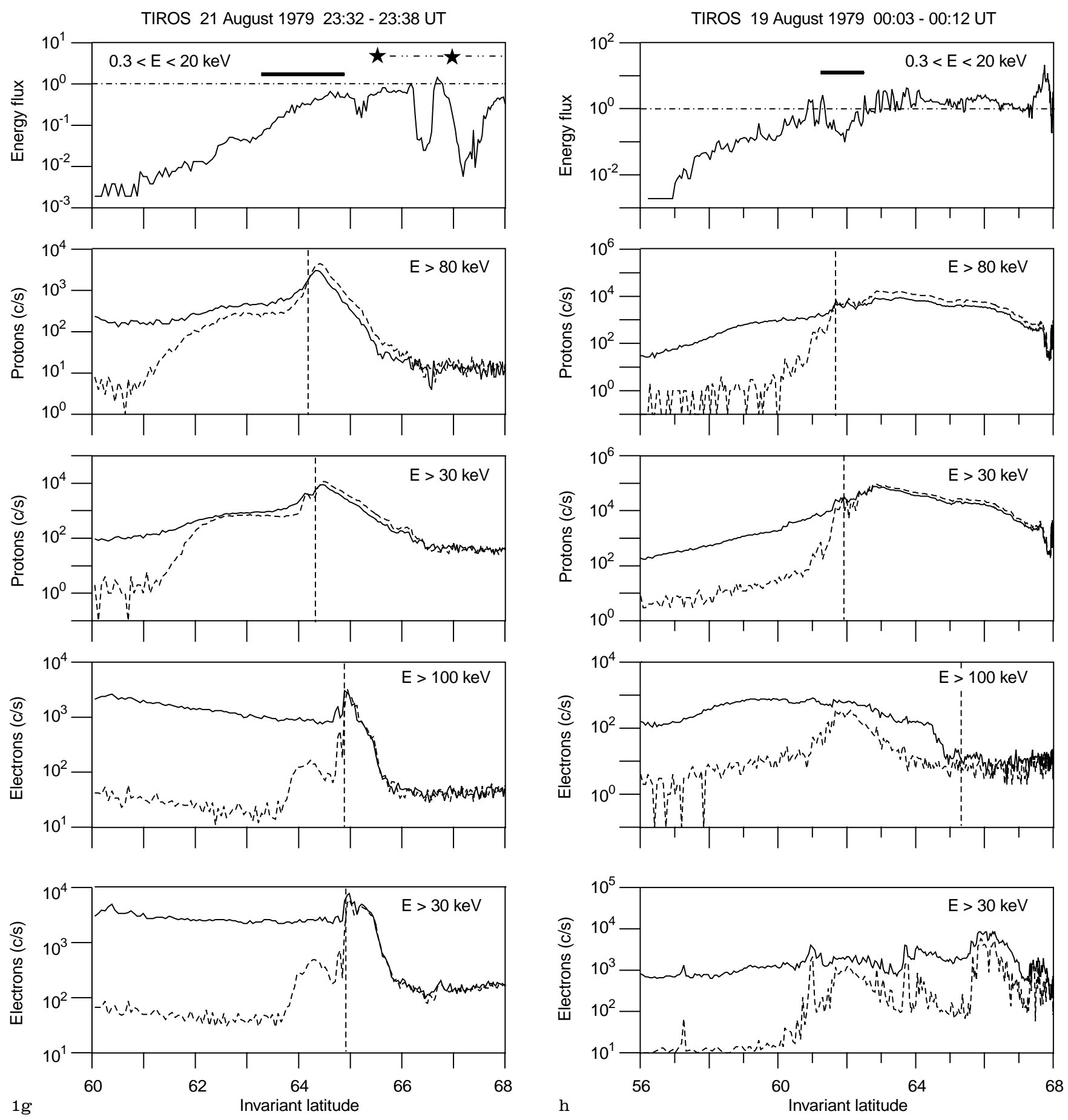

in the equatorial part (inv. lat. $=60-65$ ) and bright discrete auroras grouping in the poleward part (inv. lat. $=70-73)$, therefore representing a nice example of the "double oval". Short-lived dynamic discrete forms sometimes appeared between these main structures.

Two northern-hemisphere passes over the ground stations recording auroras took place at $\sim 17: 25$ and 20:44 UT (Events 10 and 11, respectively). During event 10 (Figs. 1j and 3a) the aurora was observed over Greenland and Kola peninsula. At Scoresbysund (situated at inv. lat. $=71.8$ and MLT $=18: 30)$ the bright

discrete auroras were seen at inv. lat. $=70-75$. At the same time (although at different MLT) the camera at Loparskaya (inv. lat. $=64.4$, MLT $=21: 30$ ) observed the diffuse aurora below inv. lat. $=64.5$; also the bright discrete forms were seen at the northern horizon (Fig. 3a). The polar edge of the diffuse aurora was bordered by the arc-like structure. The NOAA-6 satellite crossed the auroral zone at MLT $=19: 15$. The IBs for $>30,>100$ and $>300-\mathrm{keV}$ electrons were detected at inv. lat. $=\sim 70, \sim 67$ and $\sim 65$, respectively. The latitude of the proton IB is inside the latitudinal range of 

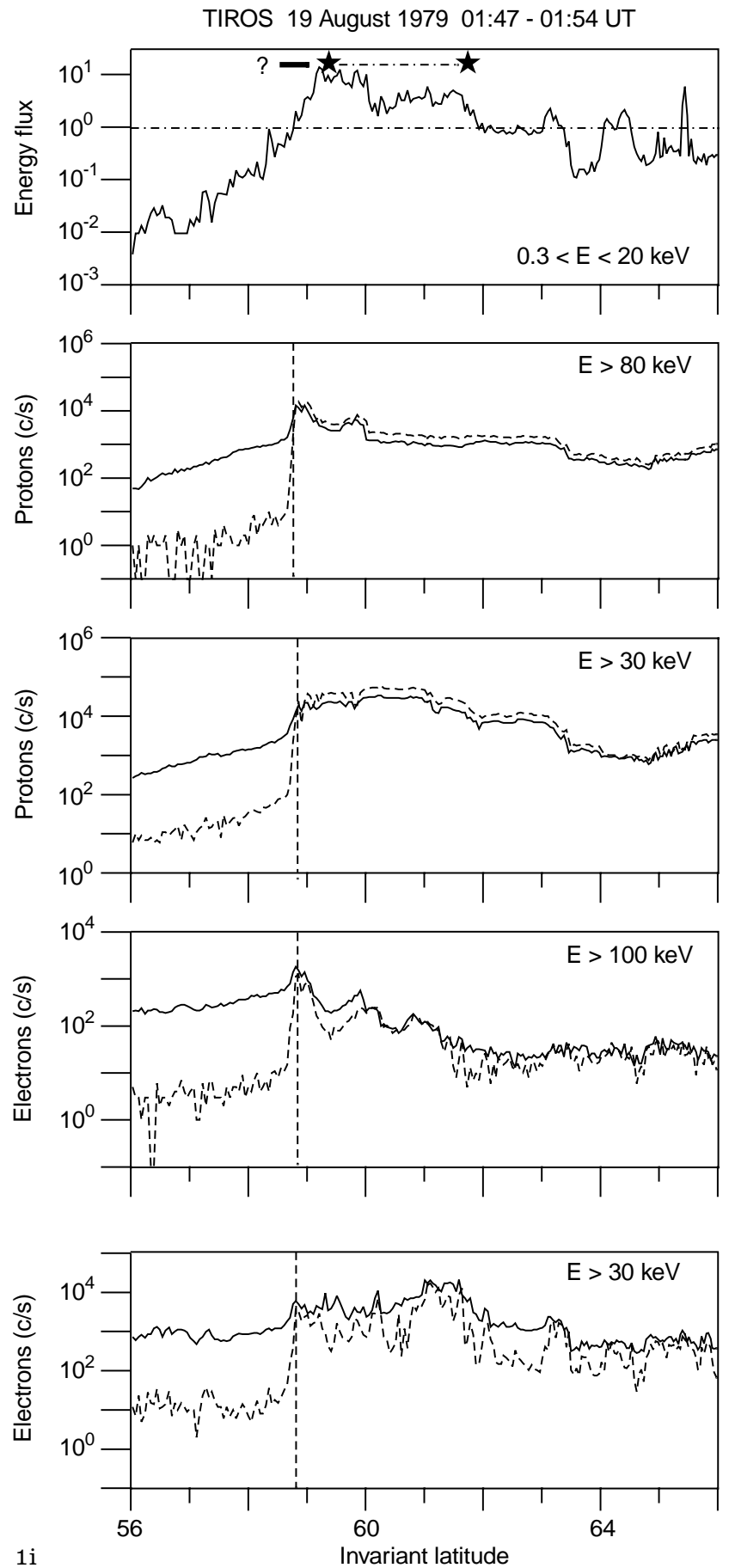

the diffuse auroral band. (In fact the comparison of IB with the diffuse auroras is limited by the fact that the satellite trace is as far to the west from the location of Loparskaya as $2 \mathrm{~h}$ of MLT).

During Event 11 (Figs. 1k and 3b) the auroral data were obtained from the stations Narssarssuaq, Scoresbysund and Sondre Stromfjord. The bright discrete auroras were seen at inv. lat. $=70-73$ and some weak arcs were also observed in the southern sky of Narssarssuaq. The IBs for $>30,>100$ and $>300-\mathrm{keV}$ electrons were found at inv.lat. $=64.5$ and a second IB for $>30-\mathrm{keV}$ electrons was detected close to the zenith
NOAA-6 24 November 1981 17:21 - 17:26 UT
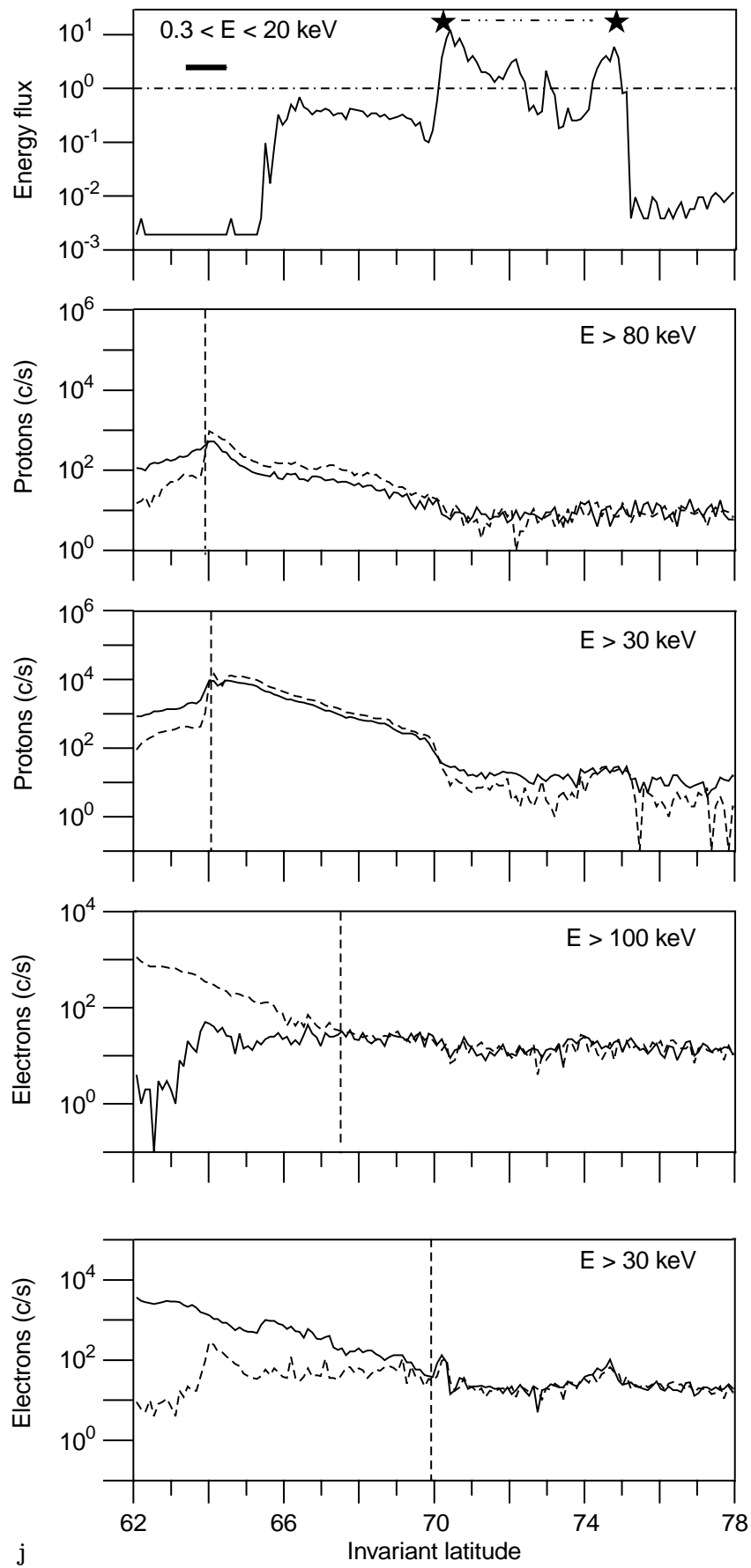

of the station Narssarssuaq; the proton IB was at inv. lat. $=63.5$.

\subsection{Auroras and low-energy $(0.3-20-k e V)$ precipitation structures}

Now let us compare how the auroral forms observed by the all-sky camera correspond to the total precipitated energy flux measured by the spacecraft. Let us return to Fig. 1 (upper panel) where the locations of auroral forms are marked on the traces of energy flux of the 

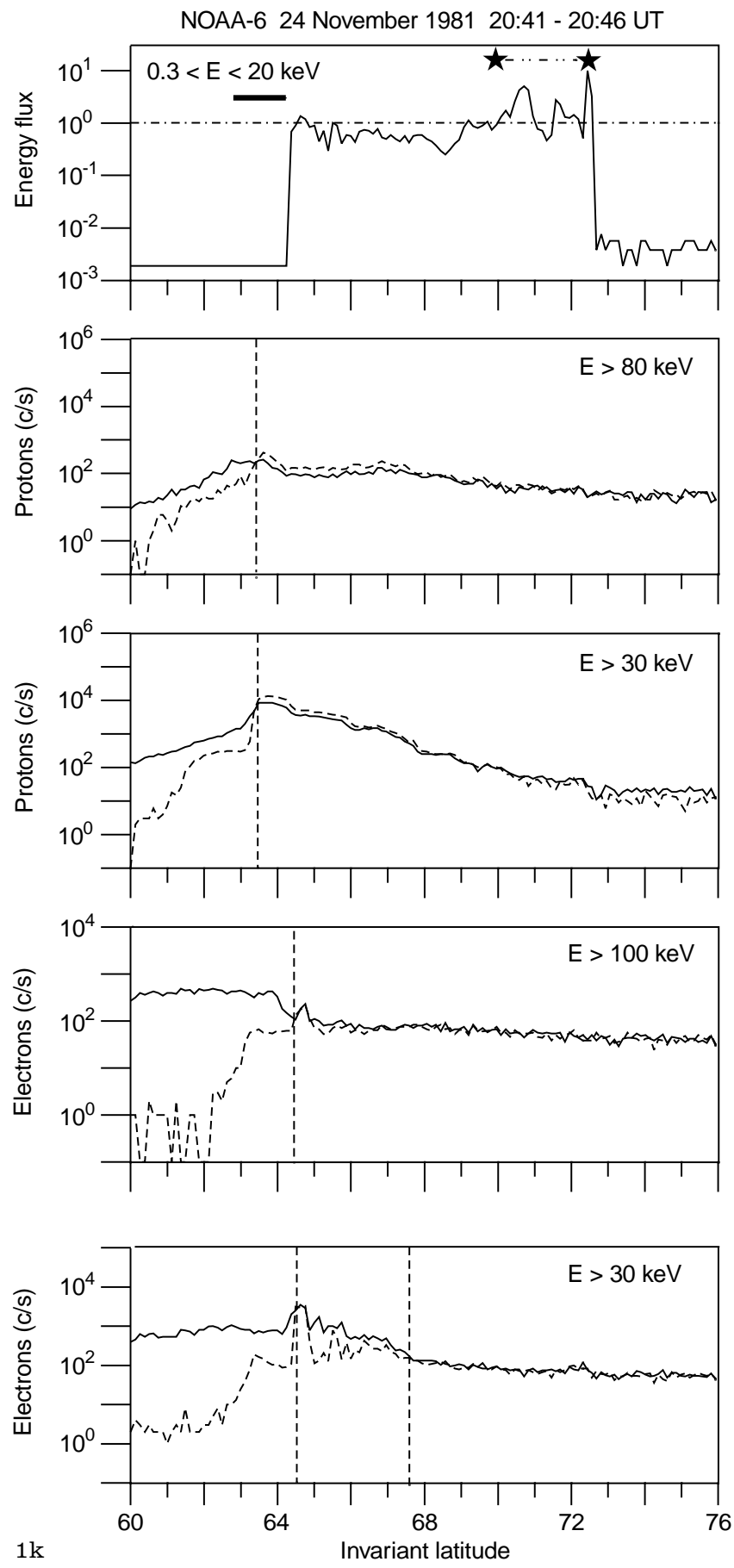

auroral electrons. The discrete auroral arcs typically correspond to spikes of energy flux (we cannot say anything about detailed correspondence because the accuracy of the arc positioning is not very high, especially at large zenith angles). On the upper panel of Fig. 1 the level of electron energy flux corresponding to $1 \mathrm{ergs} / \mathrm{cm}^{2 *} \mathrm{~s}$ sr is shown (this level is often cited as the approximate threshold of seeing the auroras on ascafilms). This level divides roughly the precipitation into two categories corresponding to relatively "high" and "low" intensity of precipitation flux. Similar to the visual auroral arcs the auroral precipitation spikes lie mainly polewards from the energetic electron IB. The main body of the CPS-like precipitation is equatorward from the electron IB. But, in contrast to the visual diffuse auroral forms already described, in some cases the low-latitudinal cut-off of this $0.3-20-\mathrm{keV}$ electron precipitation is observed poleward from the proton IB (Events 1-3).

\section{Summary of observations}

We considered 11 events of correlated observations of the particles on board the NOAA/TIROS satellites and the auroral observations from the ground. In 10 crossings the discrete auroral forms were observed, in 4 of them diffuse auroras were seen. All comparisons have been made in the local-time-sector between 18 and $01 \mathrm{~h}$ MLT. Main results of comparisons can be summarised as follows.

1. In 8 of 10 cases the arcs were observed poleward of $>30-\mathrm{keV}$ electron IB. In two other cases (Events 4 and 11) which are characterised by the double $30-\mathrm{keV}$ electron IB structure, the most equatorward arcs have been found between the $30-\mathrm{keV}$ electron IBs in the region of empty loss cone but nevertheless well inside the region of filled loss cone of the $>100-\mathrm{keV}$ electrons. Thus, all discrete arcs (quiet and disturbed) have been found inside the isotropic precipitation of energetic electrons.

2. The preceding statement seems to be valid for the large range of positions of discrete arcs: from poleward boundary of auroral zone at inv. lat. $=75$ (Events 10 and 11) down to inv. lat. $=60$ (Event 9). It is also valid for a wide range of activity and cover quiet states $(\mathrm{AE}=50 \mathrm{nT}$, Event 6), substorms (up to $1000 \mathrm{nT}$ in AE index, Event 9) and the SMC events as well.

3. Locations of the discrete arcs coincided with the peaks in the low-energy-flux latitudinal profile (Fig. 1). The peaks were poleward from the electron IBs.

4. The diffuse aurora has been observed equatorward of the $30-\mathrm{keV}$ electron IB.

5. The proton IBs have been found inside the region of the diffuse auroras. But in some cases the proton IBs were situated equatorwards of the low-latitudinal cut-off of $0.3-20-\mathrm{keV}$ precipitation.

Here we would like to compare our results with earlier results of Sergeev et al. (1983) and Kirkwood and Eliasson (1990) obtained for the substorm growth phase (i.e. for a situation not included in our survey). These authors based analysis only on ground observations, comparing the positions of discrete arcs and diffuse bands with a so-called "energetic electron arc" [EEA, a latitudinally narrow belt of enhanced D-region ionisation produced by the energetic electron precipitation from the outer edge of the electron radiation belt (e.g. Rossberg, 1976; Ranta, 1978)]. Sergeev et al. (1983) used all-sky and riometer observations, whereas Kirkwood and Eliasson (1990) used EISCAT radar to locate these features, but the results were the same: discrete auroras were always observed poleward of (or right at) the EEA, and diffuse auroras were always seen equatorward of the EEA. By noticing that the narrow and intense spike of 
Table 2. Summary of observations

\begin{tabular}{|c|c|c|c|c|c|c|c|c|c|}
\hline $\begin{array}{l}\text { No. } \\
\text { of event }\end{array}$ & date & $\begin{array}{l}\text { time } \\
\text { UT }\end{array}$ & $\begin{array}{l}\text { MLT } \\
\text { sector }\end{array}$ & $\begin{array}{l}\text { discrete } \\
\text { auroras }\end{array}$ & $\begin{array}{l}\text { diffuse } \\
\text { auroras }\end{array}$ & $\begin{array}{l}\text { latitude of } \\
\text { electron IBs }\end{array}$ & $\begin{array}{l}\text { latitude of } \\
\text { proton IBs }\end{array}$ & $\begin{array}{l}\text { geomagnetic } \\
\text { conditions }\end{array}$ & $\begin{array}{l}\text { reference to } \\
\text { figure }\end{array}$ \\
\hline 1 & $27 / 08 / 79$ & $18: 17$ & $\begin{array}{l}\text { evening } \\
18-19\end{array}$ & $\begin{array}{l}\Lambda=69.5 \\
\text { Bright arc }\end{array}$ & & $\Lambda_{\mathrm{E} 1}=68.7$ & $\Lambda_{\mathrm{P} 1}=65.6$ & $\begin{array}{l}\text { moderate } \\
\text { activity }\end{array}$ & $\begin{array}{l}\text { Fig. 1a } \\
\text { Fig. 2a }\end{array}$ \\
\hline 2 & $26 / 08 / 79$ & $18: 39$ & $\begin{array}{l}\text { evening } \\
18-19\end{array}$ & $\begin{array}{l}\Lambda=68 \\
\text { Weak arc }\end{array}$ & & $\Lambda_{\mathrm{E} 1}=67.5$ & $\Lambda_{\mathrm{P} 1}=65$ & $\begin{array}{l}\text { moderate } \\
\text { substorm }\end{array}$ & $\begin{array}{l}\text { Fig. 1b } \\
\text { Fig. 2b }\end{array}$ \\
\hline 3 & $21 / 08 / 79$ & $18: 46$ & $\begin{array}{l}\text { evening } \\
18-19\end{array}$ & $\begin{array}{l}\Lambda=70.2 \\
\text { Bright arc }\end{array}$ & & $\Lambda_{\mathrm{E} 1}=70$ & $\Lambda_{\mathrm{P} 1}=65.4$ & $\begin{array}{l}\text { small } \\
\text { disturbance }\end{array}$ & $\begin{array}{l}\text { Fig. 1c } \\
\text { Fig. 2c }\end{array}$ \\
\hline 4 & $15 / 08 / 79$ & $19: 14$ & $\begin{array}{l}\text { evening } \\
18-20\end{array}$ & $\begin{array}{l}\Lambda=69.8 \\
\text { Weak arc }\end{array}$ & & $\Lambda_{\mathrm{E} 1}=69$ & $\Lambda_{\mathrm{P} 1}=67.5$ & $\begin{array}{l}\text { small } \\
\text { disturbance }\end{array}$ & $\begin{array}{l}\text { Fig. 1d } \\
\text { Fig. 2d }\end{array}$ \\
\hline 5 & $01 / 08 / 79$ & $22: 06$ & $\begin{array}{l}\text { midnight } \\
23-01\end{array}$ & $\begin{array}{l}\Lambda=66.5 \\
\text { bright arc }\end{array}$ & & $\Lambda_{\mathrm{E} 2}=64.8$ & $\Lambda_{\mathrm{P} 1}=63$ & $\begin{array}{l}\text { interval } \\
\text { between two } \\
\text { substorms }\end{array}$ & $\begin{array}{l}\text { Fig. 1e } \\
\text { Fig. 2e }\end{array}$ \\
\hline 6 & $15 / 08 / 79$ & $22: 56$ & $\begin{array}{l}\text { midnight } \\
23-24\end{array}$ & $\begin{array}{l}\Lambda=69.5 \\
\text { weak arc }\end{array}$ & & $\Lambda_{\mathrm{E} 1}=68.5$ & $\Lambda_{\mathrm{P} 1}=67$ & $\begin{array}{l}\text { quiet } \\
\text { conditions }\end{array}$ & $\begin{array}{l}\text { Fig. 1f } \\
\text { Fig. 2f }\end{array}$ \\
\hline 7 & $21 / 08 / 79$ & $23: 34$ & $\begin{array}{l}\text { midnight } \\
00-01\end{array}$ & $\begin{array}{l}\Lambda=65-67 \\
\text { weak aurora }\end{array}$ & $\begin{array}{l}\Lambda=63-65 \\
\text { weak } \\
\text { aurora }\end{array}$ & $\Lambda_{\mathrm{E} 1}=65$ & $\begin{array}{l}\Lambda_{\mathrm{P} 1}=64.5 \\
\Lambda_{\mathrm{P} 3}=63.5\end{array}$ & $\begin{array}{l}\text { moderate } \\
\text { activity }\end{array}$ & $\begin{array}{l}\text { Fig. 1g } \\
\text { Fig. } 2 g\end{array}$ \\
\hline 8 & $19 / 08 / 79$ & $00: 10$ & $\begin{array}{l}\text { midnight } \\
23-01\end{array}$ & & $\begin{array}{l}\Lambda=61-63 \\
\text { bright } \\
\text { diffuse band }\end{array}$ & $\Lambda_{\mathrm{E} 2}=65$ & $\begin{array}{l}\Lambda_{\mathrm{P} 1}=62 \\
\Lambda_{\mathrm{P} 3}=61\end{array}$ & $\begin{array}{l}\text { strong } \\
\text { substorm }\end{array}$ & $\begin{array}{l}\text { Fig. 1h } \\
\text { Fig. } 2 \mathrm{~h}\end{array}$ \\
\hline 9 & $19 / 08 / 79$ & 01:49 & $\begin{array}{l}\text { midnight } \\
00-01\end{array}$ & $\Lambda=60-66$ & $\begin{array}{l}\Lambda=58-58.5 \\
\text { bright } \\
\text { diffuse band }\end{array}$ & $\Lambda_{\mathrm{E} 1}=58.5$ & $\Lambda_{\mathrm{P} 1}=58.5$ & $\begin{array}{l}\text { strong } \\
\text { substorm }\end{array}$ & $\begin{array}{l}\text { Fig. 1i } \\
\text { Fig. 2i }\end{array}$ \\
\hline 10 & $24 / 11 / 81$ & $17: 25$ & & $\begin{array}{l}\Lambda=70-75 \\
\text { bright } \\
\text { auroras }\end{array}$ & $\begin{array}{l}\Lambda=63-64 \\
\text { diffuse band }\end{array}$ & $\begin{array}{l}\Lambda_{\mathrm{E} 1}=69.5 \\
\Lambda_{\mathrm{E} 2}=67.5 \\
\Lambda_{\mathrm{E} 3}=65.5\end{array}$ & $\Lambda_{\mathrm{P} 1}=64.5$ & SMC & $\begin{array}{l}\text { Fig. } 1 \mathrm{j} \\
\text { Fig. 3a }\end{array}$ \\
\hline 11 & $24 / 11 / 81$ & $20: 44$ & $\begin{array}{l}\text { late } \\
\text { evening } \\
19-20\end{array}$ & $\begin{array}{l}\Lambda=70-72 \\
\text { bright } \\
\text { auroras } \\
\Lambda=64-65\end{array}$ & & $\begin{array}{l}\Lambda_{\mathrm{E} 1}=67.5 \\
\Lambda_{\mathrm{E} 1-3}=64.5\end{array}$ & $\Lambda_{\mathrm{P} 1}=63.5$ & SMC & $\begin{array}{l}\text { Fig. 1k } \\
\text { Fig. 3b }\end{array}$ \\
\hline
\end{tabular}

energetic electron precipitation is typically seen right at the position of the isotropic boundary of these energetic electrons at the nightside (see Fig. 1g), this means essentially the same result as we obtained using the low-altitude spacecraft observations. Therefore, the same conclusion can be extended to the situations of the substorm growth phase as well.

\section{Discussion}

\subsection{Current sheet as the source region of the discrete auroras}

As discussed in Sect. 1, there exist different dynamic states of the magnetosphere during which the discrete auroras tend to appear (or are more intense) in very different physical domains, far-tail and near-Earth plasma sheet, in the regions being very different in their physical parameters. A natural question then is: Are these arcs generated by the same or different mechanisms? Galperin (1994) suggested that the mechanisms responsible for the generation of these arcs should be different because the plasma and magnetic-field conditions in the inner and far-tail plasma-sheet domains differ so significantly. This question is also important for understanding the substorm onset, which starts from the most equatorial arc, as well as for substorm-like activations (pseudo-breakups) which usually occur polewards of that equatorward arc.
There exist some morphological facts which allow us to believe that the mechanism of arc formation may be the same in both domains. First of all, as discussed by Sergeev and Yahnin (1979) (see also Elphinstone et al., 1996), the most poleward arc system (or the poleward part of the "double oval", believed to map into the far tail) is very often the remnant of the auroral bulge, which developed in the course of the preceding substorm. However, this preceding auroral bulge started as the activation of a most equatorial arc (believed to be

Fig. 2. a. Top: AE index for 27 August 1979. The time of Event 1 is marked by a black arrow. Bottom: Map in coordinates MLT- inv. lat. showing the single discrete arc (dashed line) observed in the field of view of the all-sky camera at Molodezhnaya during the NOAA-6 satellite pass for Event 1. Approximate field of view of the all-sky camera is shown by the solid-line oval. Trace of the satellite is shown by solid line. The electron and proton IBs are shown on the trace of the satellite by open circles and asterisks. b Likewise for Event 2. c Event 3. d Event 4. e Event 5. The IBs were obtained from the TIROS satellite measurements. f Event 6 . The IBs were obtained from the TIROS satellite measurements. g Event 7. Both discrete and diffuse auroras were observed in this case. The diffuse aurora is shown by the hatched area. The IBs were obtained from the TIROS satellite measurements. h Event 8 . The diffuse aurora observed from Novolazarevskaya is shown by the dotted area. Note that there was no discrete aurora in this case. The IBs were obtained from the TIROS satellite measurements. i Event 9. Both discrete and diffuse auroras were observed in this case from Novolazarevskaya. Note that in this case all IBs obtained from the TIROS satellite particle measurements coincide 

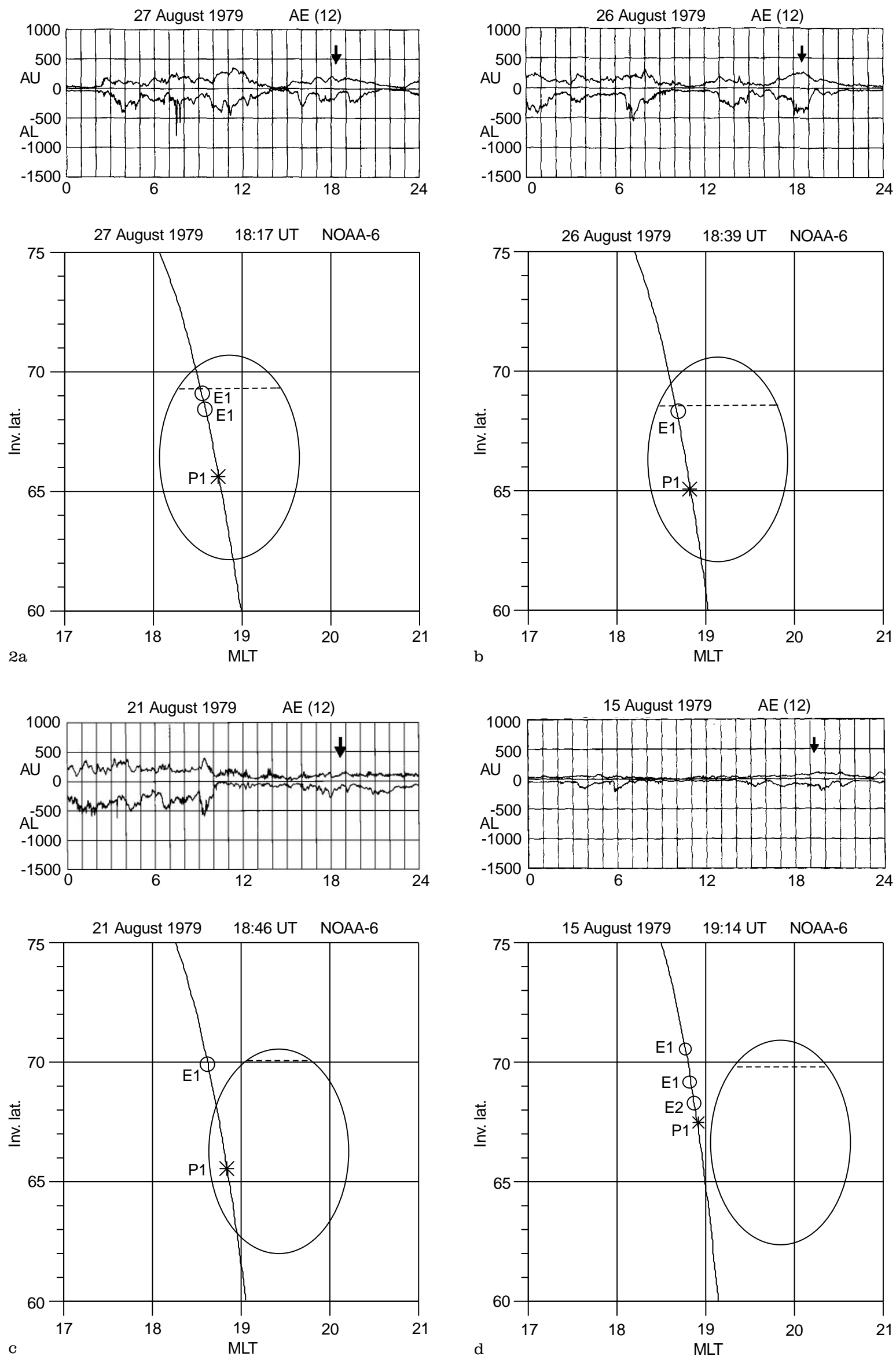

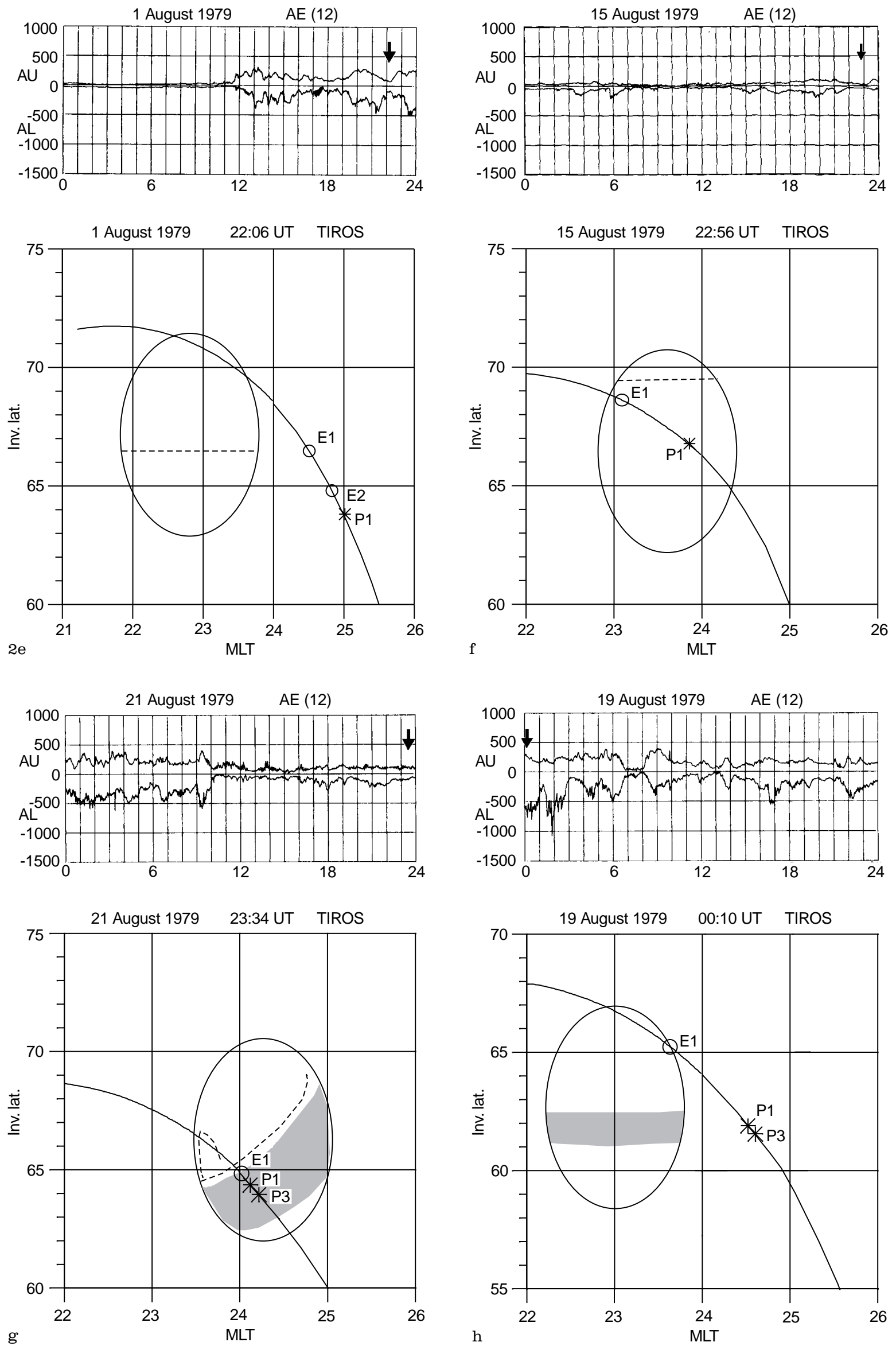

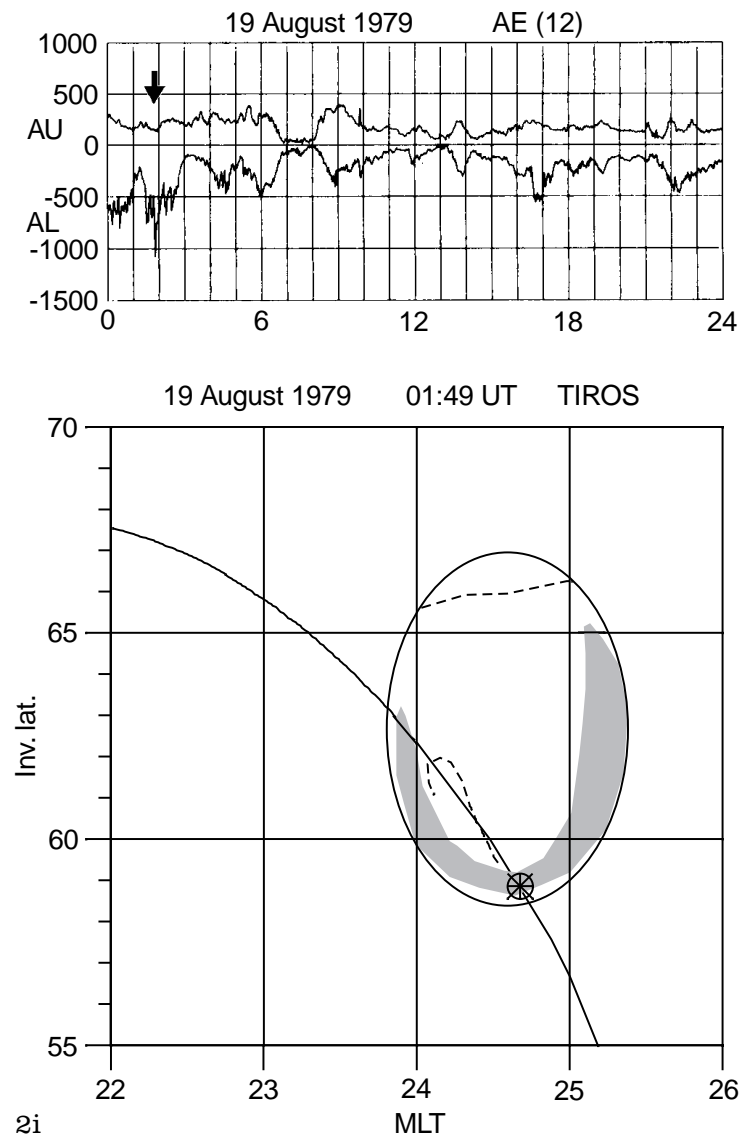

mapped to the near tail) and the poleward expansion is often a nearly continuous development, rather than the activation of the new domain (far tail) with fading of auroras coming from the near-Earth domain.

There are also some other similarities in the auroral dynamics in two regions. Often, especially in the cases of strong substorms, the bulge forms as a progressive appearance of new, more poleward arcs. Such behaviour is typical for the low latitudes where substorms start, and it is the same for the high latitudes where the bulge
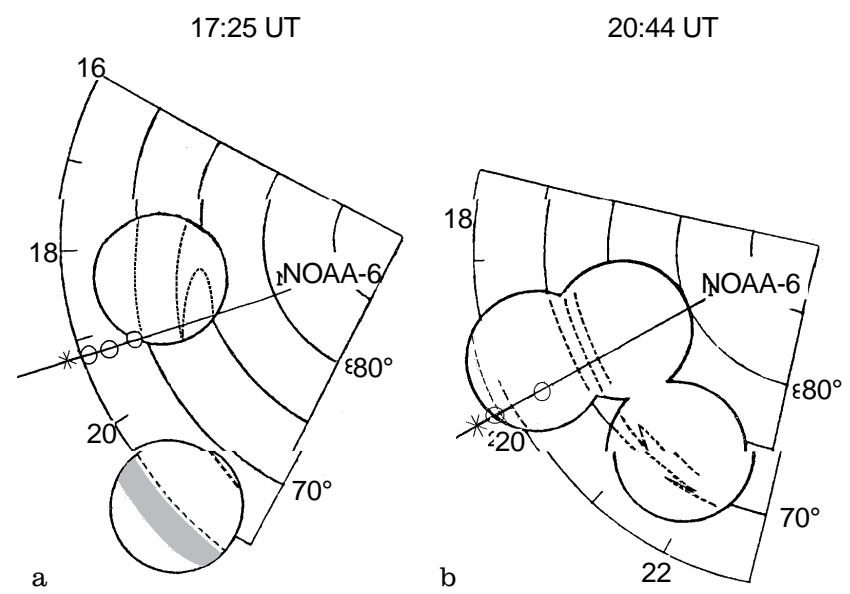

Fig. 3. Maps (in polar coordinates MLT-inv. lat.) of the aurora seen in the field of view of the all-sky cameras during the NOAA- 6 satellite passes of 24 November 1981. Left: for the event 10; right: for the event 11 expansion stops (Sergeev and Yahnin, 1979; Kornilova et al., 1990). Comparisons with other (magnetic, riometer, etc.) signatures of poleward expanding bulge also confirm that they are essentially the same at such different latitudes (Nielsen et al., 1988). Therefore, there is no observational evidence that the character of the bulge development changes in the course of the substorm when proceeding from low to high latitudes. This strongly suggests that the same arc generation mechanism acts at these different latitudes.

Our results show one important systematic feature common to low-latitude and high-latitude auroral arcs: they always appear in the regions where the energetic electrons are scattered isotropically, independently of latitude, MLT, activity, etc. To interpret this fact in physical terms we adopt the view that the isotropic precipitation of energetic particles on the nightside is basically caused by their regular scattering on highly curved magnetic field lines in the tail current sheet (there is now much evidence for this view, see e.g. Sergeev et al., 1993). Quantitative estimates given by Sergeev et al. $(1983,1993)$ for the $30-\mathrm{keV}$ electrons show that in the inner magnetotail $\left(\sim 8-12 \mathrm{R}_{\mathrm{E}}\right)$ the threshold condition for their scattering over the loss cone requires $B_{z} \sim 5$ $\mathrm{nT}$ for the average current sheet density. This can be taken as the representative estimate for the near tail. For the high current densities typical for the end of the substorm growth phase this value may increase up to $\sim 10 \mathrm{nT}$ (but it is very rare). For smaller current densities typical for the far tail, the threshold $B_{z}$ can fall to 1-3 $\mathrm{nT}$, and these are quite typical values for the far tail. The fact of isotropic precipitation, from this viewpoint, means that in the equatorial plane $B_{z}$ is less than the cited threshold values.

As noted in Sect. 4, most equatorward discrete arcs can sometimes (e.g. in the case of multiple IBs) be observed in the region of empty loss cone of the $>30$ $\mathrm{keV}$ electrons. But even in such rare cases the arcs are, anyway, in the region of isotropic precipitation of the $>100-\mathrm{keV}$ electrons. The threshold $B_{z}$ value for the particles of the same sort (electrons in our case) is proportional to $E^{1 / 2}$, where $E$ is particle energy. Thus, the threshold values of $30-$ and $100-\mathrm{keV}$ electrons will not differ dramatically. For $100-\mathrm{keV}$ electrons the estimated value must be multiplied by 1.7 and equal $8.5 \mathrm{nT}$.

Taking all this into account the interpretation of the fact that auroral arcs are always seen inside the areas with the isotropic precipitation of energetic electrons, is that the source region of the discrete auroral arcs is the intense quasi-neutral current sheet. (By this we mean the region of current sheet characterised by such a high curvature of magnetic field lines in the current sheet that $30-\mathrm{keV}$ electrons behave non-adiabatically. For normal current densities in the tail it implies a small magnetic field in the current sheet, $<5 \mathrm{nT}$ ).

Sometimes (near the substorm onset, during the SMC, during very disturbed periods, etc.) most equatorial arcs appear just at the polar edge of the diffuse aurora and at the outer boundary of the radiation belt. There is no contradiction between this observation and 
our interpretation. It is known that at the end of the growth phase the magnetotail current sheet strongly grows, especially in the near-Earth region, and that $B_{z}$ falls to a few nT in that region (Pullkinen et al., 1991). A similar situation has also been inferred for the SMC interval (Sergeev et al., 1996; Yahnin et al., 1994b). The enhanced current sheet produces the magnetic field configuration with the large Earthward gradient of the $B_{z}$ component of the magnetic field. Because of this large magnetic field gradient, the structures which are close to each other at the ionospheric level might be mapped into regions with different magnetic configuration in the equatorial plane (dipole-like and very stretched). In such cases very close colocation of the electron and proton IBs is expected as well. According to this view, we expect a very strong current sheet located close to the Earth during, for example, Events 7 and, especially, 9.

The conclusion that the intense quasi-neutral current sheet is a source region for the auroral arcs confines the choice of the instabilities which can be responsible for the generation of the auroral arcs. One of the possibilities is the tearing instability leading to the magnetic reconnection in the current sheet. This choice allows to incorporate the auroral-arc generation and dynamics in the frame of modified "neutral line model" for the substorms. A further discussion on that subject is beyond the scope of our paper.

\subsection{Magnetic field in the source regions of diffuse auroras}

In the light of the estimations made by Sergeev et al. (1993) for the threshold magnetic field value for energetic protons the diffuse auroras are on the quasidipole magnetic field lines where the equatorial plane magnetic field is of some tens of nT. It is in agreement with the rather common view that diffuse auroras originate from the near-Earth magnetotail where the magnetic field is dipole-like and where the loss cone is relatively large (the favourite condition for the pitchangle diffusion due to the wave-particle interaction) and changes smoothly. The latter explains why the aurora in this region is diffuse, i.e. does not show a significant latitudinal structure. It should be noted that in fact the weak diffuse aurora can be observed across the whole auroral zone until the polar-cap boundary (e.g. Feldstein and Galperin, 1985), but the most intense luminosity is expected to be mapped to the region of the large loss cone.

\subsection{Comparison with other schemes of source regions for particle precipitation}

As we showed in Sect. 1 and have discussed throughout this paper, the existing different schemes of magnetospheric sources for auroral structures (e.g. those by Lyons et al. and Feldstein and Galperin) may not be mutually exclusive and so contradictory, rather they may both be valid for different particular situations in the dynamic magnetotail. In this section we (1) show how our conclusion on the intense quasi-neutral current sheet as the source of auroral arcs agree or disagree with the observational facts provided by the proponents of both schemes, and (2) outline the basic differences between these schemes and our conclusions.

As regards the main point, our findings are in good agreement with the view of Feldstein and Galperin (1985). They concluded (Feldstein and Galperin, 1985, p.251) that "the separating boundary between the diffuse and discrete auroras ... is the stable trapping boundary of $>40-\mathrm{keV}$ electrons". Indeed, the energetic electron isotropy boundary associates with the stable trapping boundary. At the same time, in contrast to the view of Feldstein and Galperin and in agreement with the findings of Elphinstone et al. (1995), discrete arcs are sometimes found at high latitudes, very close to the sharp decrease in the electron energy flux which is certainly related to the outermost part of the plasma sheet (Fig. 1j, k, the SMC event of 24 November 1981). Lyons and Evans (1984) considered the particle data obtained on board the NOAA- 6 satellite. They found bursts of the low-energetic $(<20-\mathrm{keV})$ electrons, which they associated with discrete auroras, to be embedded into the region where both energetic electrons and energetic protons were isotropic. Lyons et al. (1988) found the low-energy electron precipitation bursts to be located in the poleward part of the isotropic proton precipitation. Our results confirm these findings. Lyons et al. (1988) suggested that the proton isotropy is produced by the particle scattering in the current-sheet region, thus concluding that the discrete aurora originate from the farthest part of the magnetotail. This led them to the conclusion that discrete aurora are from the PSBL. However, the energetic protons are isotropic even in the region where the $B_{z}$ component of the magnetic field is several tens of nT (see Sergeev et al., 1993). As we have discussed, it is more reasonable to consider the current sheet as a region of isotropy of energetic electrons. To show schematically in which points our results and interpretation agree and disagree with different views to the source of the discrete auroras we summarise these views in Fig. 4. As the basis we adopt Fig. 2 of Lyons (1992) and show it at the top of our figure. Figure 4 shows schematically four magnetic field lines at the nightside of the magnetosphere dividing the magnetotail into the important regions. The closest to the Earth is the dipole-like field line where $B_{z}$ component of the magnetic field in the equatorial plane is some tens of nT. Next, further to the tail, is the field line with $B_{z}=5 \mathrm{nT}$ at the equatorial plane. We consider the current sheet as the region where $B_{z}$ is only some nT, thus this line marks the inner edge of the current sheet. Then we draw the inner boundary PSBL (of course, not to scale). The last field line connects the ionosphere with the distant neutral line [note that Lyons (1992) did not mentioned any values in his scheme]. In Lyons' scheme the discrete auroras correspond to the part of the current sheet between lines 3 and 4 . The diffuse auroras are linked with the region Earthward of line 3. In the middle of the figure, the view advocated by Feldstein and Galperin (1985) is presented (see also Galperin and 
After Lyons (1992)

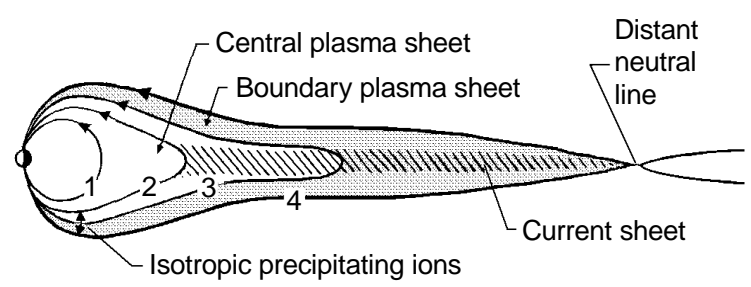

After Feldstein and Galperin (1985)

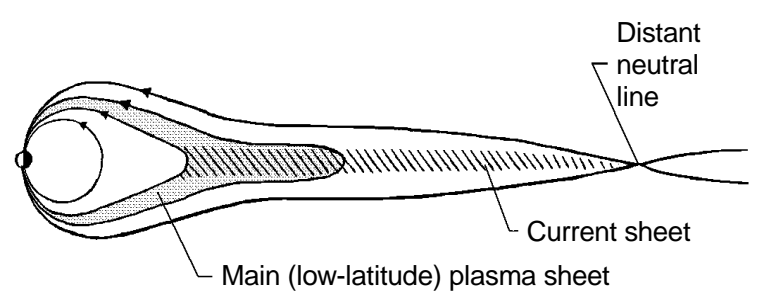

After this paper

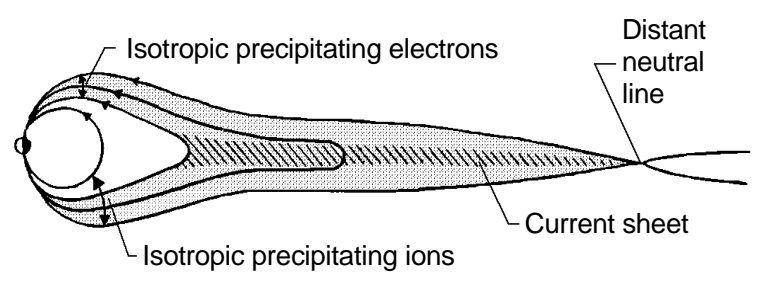

Fig. 4. Schematic presentation of different views to the source region of auroras [adopted from Lyons (1992)]. Each of three panels shows the midnight meridian cross-section of the plasma sheet. Field line 1 is a dipole-like magnetic field line $\left(B_{z}=30-50 \mathrm{nT}\right.$ at the top of it); tailward of line $2 B_{z}<5-8 \mathrm{nT}$ (current sheet); line 3 corresponds to inner edge of PSBL, and line 4 marks the outer edge of the plasma sheet. The upper panel reproduces the view advocated by Lyons and co-workers, the middle panel represents the view of Feldstein and Galperin, and in the bottom the result of this study is presented. The hatched region means the current sheet; the dotted area on each panel shows the region of discrete auroras according to the views of different authors

Feldstein, 1991; Feldstein and Elphinstone, 1992). They connect the discrete aurora region with the region between lines 2 and 3, suggesting that the diffuse aurora source lies Earthwards of the line 2 or the inner edge of the plasma sheet which is associated by these authors with the inner edge of the current sheet. At the bottom we present the view corresponding to the result of this paper. We put the discrete and diffuse aurora sources into the entire current sheet and dipole-like magnetic field, respectively. In fact, our discrete aurora source region combines that shown in the top and middle panels. The difference between the interpretations of the isotropic proton precipitation boundaries as suggested by Lyons and co-workers and our view is clearly seen from the comparison of top and bottom parts of the figure.

The main difference between our scheme and those shown in the top and middle panels of Fig. 4 is that we do not fix the radial location of the discrete aurora source; it can be at different places in the tail depending on the current state of the magnetosphere. It can be at the inner edge of the magnetotail current sheet at the end of substorm growth, but, if the growth phase occurs after an enhanced magnetic activity interval, the source(s) could be located both in the inner and outer plasma sheet. A similar situation is expected during the SMC intervals. During the substorm expansion phase the discrete aurora source progressively occupies the current sheet propagating from the near-Earth to the far current sheet (between lines 2 and 4 in the scheme). During strong substorms it likely stops at the location of the distant neutral line which marks the transition region between open and closed field lines. During quiet and growth-phase intervals the source of the discrete auroras can be in the middle tail, producing the quiet arcs and pseudo-breakups.

\section{Conclusion}

From comparison of ground observations of auroral forms with meridional profiles of particle flux measured simultaneously by the low-altitude NOAA satellites above the ground observation region, we found discrete auroral arcs to be bounded from the equatorward side by the isotropic boundary IB of energetic electrons, whereas the IB of energetic protons is often seen inside the diffuse aurora. These relationships hold true for both quiet and active (substorm) conditions in the premidnight-nightside (18-01-h) MLT sector considered.

The results presented here support the idea of the mechanism of the discrete arcs being related to the current sheet. We conclude also that there should be no difference between the mechanism responsible for generation of arcs from different parts of the current sheet. It could be some current-sheet instability resulting in the reconnection. We have to note that in spite of the fairly large set of satellite data (about 1 month) we have found only a few events appropriate for the comparison with the ground observations. This is one of the limitations of our conclusion. Another is that the morning sector has not been taken into consideration. Thus analysis of the extended data set is required.

Acknowledgements. Data from NOAA spacecraft have been made available through WDC-A (Boulder). We thank T. Bösinger and $\mathrm{K}$. Mursula for their help in providing us with these data. Auroral data have been obtained from WDC-B, Auroras (Apatity) and from WDC-C (Copenhagen). The work was partly supported by the ISF (grant NWT000) and INTAS (grant 94-1695).

Topical Editor K.-H. Glaßmeier thanks C. I. Meng and W. Heikkila for their help in evaluating this paper. 


\section{References}

Akasofu, S.-I., Polar and magnetospheric substorms, Reidel, Dordrecht, 1968.

Eastman, T. E., L. A. Frank, W. K. Peterson, and W. Lennartsson, The plasma sheet boundary layer, J. Geophys. Res., 89, 1553$1572,1984$.

Elphinstone, R. D., J. S. Murphree, D. J. Hern, L. L. Cogger, I. Sandahl, P. T.Newell, D. M.Klumpar, S. Ohtani, J. A. Sauvaud, T. A. Potemra, K. Mursula, A. Wright, and M. Shapshak, The double oval UV luminosity distribution. 1. Implication for the mapping of auroral arcs, J. Geophys. Res., 100, 1207512092, 1995.

Elphinstone, R. D., J. S. Murphree, and L. L. Cogger, What is a global auroral substorm, Rev. Geophys., 34, 169-232, 1996.

Feldstein, Y. I., and R. D. Elphinstone, Aurorae and the large-scale structure of the magnetosphere, J. Geomag. Geoelectr., 44, 1159-1174, 1992.

Feldstein, Y. I., and Y. I. Galperin, The auroral luminosity structure in the high-latitude upper atmosphere: its dynamics and relationship to the large-scale structure of the Earth's magnetosphere, Rev. Geophys., 23, 217-275, 1985.

Galperin, Y. I., Stable auroral arcs: observations and models, in Substorm 2, Proc. 2nd Int. Conf. Substorms, Fairbanks, Alaska, March 7-11 1994, Eds. J. R. Kan, J. D. Craven, and S.-I. Akasofu, Geophysical Institute, University of Alaska, Fairbanks, p. 383-390, 1994.

Galperin, Y. I., and Y. I. Feldstein, Auroral luminosity and its relationship to the magnetospheric plasma domains, in Auroral physics, Eds. C.-I. Meng, M. J. Rycroft, L. A. Frank, Cambridge University Press, Cambridge, pp. 207-222, 1991.

Hill, V. D., D. S. Evans, and H. H. Sauer, TIROS/NOAA satellites space environment monitor, archive tape documentation, NOAA Tech. Mem. ERL SEL-71, Environs. Res. Lab., Boulder, Colo., 1985

Kirkwood, S., and L. Eliasson, Energetic particle precipitation in the substorm growth phase measured by EISCAT and Viking, J. Geophys. Res., 95, 6025-6034, 1990.

Kornilova, T. A., M. I. Pudovkin, and G. V. Starkov, Fine auroral structure near the poleward boundary of the auroral bulge during breakup phase, Geomagn. Aeron., 30, 250-254, 1990.

Kovrazhkin, R. A., J. M. Bosqued, L. M. Zeleny, and N. V. Georgio, Observation of evidence of reconnection and plasma acceleration at a distance of about $5 \times 10^{5} \mathrm{~km}$ in the tail of the Earth's magnetosphere, JETP Lett., 45, 479-482, 1987.

Lyons, L. R., Evidence concerning the magnetosphere source region for auroral breakup, Proc. Int. Conf. Substorms (ICS-1), Kiruna, Sweden, 23-27 March 1992 (ESA SP-335), pp. 257-261, 1992.

Lyons, L. R., and D. S. Evans, An association between discrete aurora and energetic particle boundaries, J. Geophys. Res., 89, 2395-2400, 1984.

Lyons, L. R., J. F. Fennell, and A. L. Vampola, A general association between discrete auroras and ion precipitation from the tail, J. Geophys. Res., 93, 12932-12940, 1988.
Newell, P. T., Y. I. Feldstein, C.-I. Meng, and Y. I. Galperin, Morphology of nightside precipitation, J. Geophys. Res., 101, 10737-10748, 1996.

Nielsen, E., J. Bamber, Z.-S. Chen, A. Brekke, A. Egeland, J. S. Murphree, D. Venkatesan, and W. I. Axford, Substorm expansion into the polar cap, Ann. Geophysicae, 6, 559-572, 1988.

Pulkkinen, T. I., D. N. Baker, D. H. Fairfield, R. J. Pellinen, J. S. Murphree, R. D. Elphinstone, R. L. McPherron, J. F. Fennell, R. E. Lopez, and T. Nagai, Modelling the growth phase of a substorm using the Tsyganenko model and multi-spacecraft observations: CDAW-9, Geophys. Res. Lett., 18, 1963-1966, 1991.

Ranta, H., The onset of an auroral absorption substorm, $J$. Geophys. Res., 83, 3893-3899, 1978.

Rossberg, L., Prebay electron precipitation as seen by balloons and satellites, J. Geophys. Res., 81, 3437-3440, 1976.

Sergeev, V. A., and Yahnin A. G., The features of auroral bulge expansion, Planet. Space Sci., 27, 1429-1440, 1979.

Sergeev, V. A., A. G. Yahnin, and R. J. Pellinen, Relative arrangement and magnetospheric sources of zones of energetic electron injection, diffuse and discrete auroras during the preliminary phase of a substorm, Geomagn. Aeron., 23, 972 978, 1983.

Sergeev, V. A., M. Malkov, and K. Mursula, Testing the isotropic boundary algorithm method to evaluate the magnetic field configuration in the tail, J. Geophys. Res., 98, 7609-7620, 1993.

Sergeev, V. A., R. J. Pellinen, and T. I. Pulkkinen, Steady magnetospheric convection: a review of recent results, Space Sci. Rev., 75, 551-604, 1996.

Vorobjev, V. G., B. V. Rezhenov, and G. V. Starkov, Relation between the location of eastward electrojet, energetic electron trapped boundary, and auroras, Geomagn. Aeron., 16, 304-310, 1976.

Weiss, L. A., P. H. Reiff, R. V. Hilmer, J. D. Winningham, and G. Lu, Mapping the auroral oval into the magnetotail using Dynamics Explorer plasma data., J. Geomagn. Geoelectr., 44, 1121-1144, 1992.

Winningham, J. D., F. Yasuhara, S.-I. Akasofu, and W. J. Heikkila, The latitudinal morphology of $10-\mathrm{eV}$ to $10-\mathrm{keV}$ electron fluxes during magnetically quiet and disturbed times in the 2100-0300MLT sector, J. Geophys. Res., 80, 3148-3171, 1975.

Yahnin, A. G., M. V. Malkov, V. A. Sergeev, R. J. Pellinen, O. Aulamo, S. Vennerstøm, E. Friis-Christensen, K. Lassen, C. Danielsen, J. D. Craven, C. Deehr, and L. A. Frank, Features of steady magnetospheric convection, J. Geophys. Res., 99, 4039-4051, 1994a.

Yahnin, A. G., R. D. Belian, B. B. Gvozdevski, and M. V. Malkov, Development of the substorm ending the steady magnetospheric convection interval, in: Substorm 2, Proc. 2nd Int. Conf. Substorms, Fairbanks, Alaska, March 7-11, 1994, Eds. J. R. Kan, J. D. Craven, and S.-I. Akasofu, Geophysical Institute, University of Alaska, Fairbanks, p. 601-608, 1994b.

Zelenyi, L. M., R. A. Kovrazhkin, and J. M. Bosqued, Velocitydispersed ion beams in the nightside auroral zone: Aureol-3 observations, J. Geophys. Res., 95, 12119-12139, 1990. 